\title{
La Decisión 24 sobre capitales extranjeros en el Grupo Andino*
}

Una de las características más notables del proceso de integración andina es la prioridad otorgada a una reglamentación común sobre el tratamiento del capital extranjero, junto con una planificación adecuada de la liberalización comercial. Aun independientemente de sus resultados concretos, el hecho de que los países lograran un acuerdo respecto de esta reglamentación común, ha tenido un importante impacto político en términos del mayor apoyo prestado por todos los paises a la integración misma. ${ }^{1}$

El propósito de este artículo es analizar, desde el punto de vista económico, el sentido de las disposiciones fundamentales del Régimen Común de Tratamiento a los Capitales Extranjeros. Ese régimen fue establecido básicamente en la Decisión 24 de la Comisión del Acuerdo de Cartagena, aunque ha habido diversas decisiones posteriores para perfeccionarlo. Ninguna de éstas, sin embargo, incluyendo la más reciente adoptada después del retiro de Chile del Acuerdo (la Decisión No 104 del 30 de agosto de 1976), ha cambiado la filosofía económica del Régimen Común ni sus normas fundamentales. Por lo tanto, el análisis de este trabajo se concentrará en esas normas.

La sección 1 estudia el origen y los objetivos explícitos del Régimen Común Andino sobre Capitales Extranjeros. La sección 2 presenta sus principales disposiciones especificas y en la siguiente se analiza la racionalidad económica de ellas. A continuación, en la sección 4, se estudian algunos antecedentes sobre el efecto que ha tenido la Decisión 24 sobre el ingreso de capitales a la subregión, para terminar con una breve sección de conclusiones.

\footnotetext{
* Este artículo está basado en secciones del capitulo final de Ia Tesis de Doctorado del autor, "Economic Integration and Foreign Direct Investment Policies: The Andean Case", Departamento de Economia, M.T.T., Cambridge, Mass, agosto de 1976.

1Para constatar la importante politica otorgada a la Decisión 24 por parte de los paises, véase Tironi (1976). Acerca de la filosofía política $y$ del trasfondo de la decisión, véase Barandiaran (1976) y Valencia, J. (1975).
} 


\section{OBJETIOS DEL REGLAMENTO COMÚN}

Desde el inicio de los trabajos que llevaron a la formación del Grupo Andino, existió preocupación por el papel que debiera corresponderle a la inversión extranjera. Y'a en 1966, en la "Declaración de Bogotá", que estableció las bases doctrinarias del Acuerdo de Cartagena, los Presidentes y los representantes de los Presidentes de Colombia, Chile, Ecuador, Perú y Venezuela declararon lo siguiente: "Consideramos que el capital privado extranjero puede realizar un aporte considerable al desarrollo económico de América Latina, siempre que estimule la capitalización del país donde se radique; facilite la participación amplia del capital nacional en ese proceso y no cree obstáculos para la integración regional". "

Así, pues, el Acuerdo de Cartagena mismo concedió alta prioridad al establecimiento de una política común hacia la Inversión Extranjera Directa (IED). Ella se acordó el 31 de diciembre de 1970, expresándose en la Decisión. No 24 de la Comisión del Acuerdo de Cartagena (la más alta autoridad política del Pacto Andino), y comienza a implementarse por parte de la mayoria de los países en junio de 1971. ${ }^{3}$

De acuerdo con declaraciones explicitas de Felipe Salazar, jefe de la Junta del Acuerdo de Cartagena, cuando se discutió la Decisión 24 $y$ fue aprobada por los gobiernos, los objetivos que se perseguían a través del tratamiento común del capital extranjero eran los siguientes: ${ }^{4}$

a) Estimular la formación de capital en los paises receptores de capital foráneo;

b) Facilitar la participación amplia del capital nacional en el proceso de integración;

c) Evitar condiciones bajo las cuales Ia inversión foránea en los países pucliera obstruir la integración;

d) Coordinar la IED con los planes de desarrollo de los países;

2JUNAC/INTAY (1975), p. 253.

3En esa Época, Venczucla no habia firmado el Acuerdo de Cartagena, pero Bolivia si. Hubo algún retraso en la implementación de la Decisión 24. por parte de Colombia, motirada por problemas legales internos, de modo que este último pais y Venezuela comenzaron a aplicarla plenamente on 1973.

ESalazar, F. (1975), pp. 10-11. 
c) Facilitar el uso de tecnologia moderna, especialmente evitando las limitaciones respecto de la clistribución y venta de productos que la utilizan;

f) Otorgar estabiliclad a aquella inversión extranjera que realice 'una contribución positiva al desarrollo del país respectivo;

g) Contribuir a una distribución "equitativa" de las ganancias derivadas de la integración, especialmente en el caso de los países andinos relativamento menos desarrollados.

Es asi que, en general, la Decisión 24 no tuvo como único objetivo la mera estandarización cle las políticas nacionales con respecto al capital foráneo por parte de los países asociados. Se trató de una nueva política global, que cubria todo tipo de inversión extranjera. En la práctica, sin embargo, se orientó primordialmente hacia la inversión directa en aquellos sectores (especialmente manufacturas) que han de ser más afectados por cl proceso de integración. La Decisión 24 implica una política uniforme con respecto a las actividades que están "más intimamente relacionadas" con la integración, en tanto quet permite mayor flexibilidad a cada pais respecto de las políticats de IED destinadas a otros sectores, especialmente mineria, petróleo y otros recursos naturales. Por otra parte, cabe destacar que la Decisión 24: establece la politica común minima que debe ser acatada por todos los países asociados, dejando libertad para imponer normas adicionales o más estrictas por parte de aquellos que lo deseen.

2. DISPOSICIONES FUNDMMENTALES DE LA DECISIÓN 24

Las principales clisposiciones de la Decisión 24 son las siguientes:

10. Cacla proyecto de inversión extranjera debe ser autorizado explícitamente y registrado por la autoridad nacional competente. Por consiguiente, como norma gencrai, debería existir un patrón de admisión selectivo. La Decisión 24 recomienda excluir la IED de ciertos sectores especificos de las economins, tales como las industrias extractivas, los scrvicios públicos, los medios de comunicación de masas, la propaganda comercial y algunos otros. La reinversión de las utilidades que exceden del $5 \%$ del capital (posteriormente elevada al $7 \%$ 
mediante la Decisión 104 del 30 de agosto de 1976) también requiere de autorización explicita y de registro, y se la considera como una inversión adicional cualquiera para los efectos de repatriación y otros que se establecen ien Ia Decisión 24.

20 Se prohíbe la adquisición de empresas nacionales ya formadas excepto en circunstancias muy especiales, como, por ejemplo, de peligro de quiebra. Los inversionistas extranjeros pueden aclquirir intereses minoritarios en empresas nacionales, siempre que tales adquisiciones impliquen un incremento del capital de dicha empresa.

30 El acceso al crédito nacional, excepto los préstamos de corto plazo, se reserva sólo para las empresas nacionales o las empresas mixtas, pero no para las extranjeras. Recuérdese que la Decisión 24 define como empresas nacionales aquelias con $20 \%$ o menos de capital foráneo; empresas mixtas, si los accionistas extranjeros poseen más de 20 pero no más de $49 \%$; y empresas extranjeras si poseen más del $49 \%$ del capital.

40. Como principio general, las empresas extranjeras nuevas o ya existentes deberian convertirse o transformarse gradualmente en compañias mixtas o nacionales en un periodo máximo de 15 años, AqueIlas que estén ubicadas en los países andinos relativamente menos desarrollados (Bolivia y Ecuador), se les otorga un periodo máximo de 20 años.

La conversión de las firmas foráneas debe ajustarse a un calendario predeterminado; en el caso de las firmas extranjeras ya establecidas en los paises relativamente más avanzados, la cuota de capital nacional debe ser de por lo menos el $15 \%$ antes de finalizar el tercer año del periodo de transformación y de $45 \%$ antes del término del décimo año. Las empresas nuevas que se establezcan en esos paises, deberán tener una cuota de por lo menos $15 \%$ del capital nacional en el momento en que inicien su producción. Los bienes producidos por compañias foráneas que no deseen convertirse gradualmente en mixtas o nacionales no tendrán acceso al mercado de los demás países andinos con aranceles preferenciales (reducidos). De este modo, el control de está disposición está básicamente en las manos de los países importadores ${ }^{\circ}$. Las compañias foráneas que exportan $80 \%$ o más de su producción a terceros países, sin embargo, estarán exentas del requisito de conversión.

EEmpresas en las que el Estado o empresas estatales son propictarios de por to menos el $30 \%$ de su stock también podrí considerirselas "mixtas", siempre que el Estado o la empresa cstatal tenga "capacidad determinada sobre las decjsiones de lit empresa" (Decisión 47 de la Comisión del Acuer(lo de Cartagena).

cLas cinpresas extranjeras ya establecilas pueden comenzar a vender al mer- 
$5^{0}$ Se garantiza el libre acceso al mercado oficial cambiario, para la repatriación del capital foráneo, incluso de las remesas que resultan de la venta de capital a inversionistas, nacionales como parte del programa de transformación de la estructura de propiedad de las firmas. Las utilidades también podrán ser repatriadas libremente hasta un límite máximo de $14 \%$ del capital en cualquier año en particular (posteriormente, ese límite se subió al 20\% en la Decisión 104).

60 Finalmente, la Decisión 24 regula la transferencia de tecnología extranjera, el pago de regalías y los préstamos externos. No podrán existir acuerdos que obliguen a las compañias a obtener servicios de fuentes determinadas o que limiten sus derechos a exportar sus productos a cualquier parte del mundo.

\section{RACIONALIDAD ECONÓMYCA DE LAS PRINCIPALES NORMAS DEL RÉGIMEN COMÚN}

La característica más sobresaliente de la Decisión 24 , y que ha resultado ser también la más polémica, es el requisito de transformación gradual de las empresas en mixtas o nacionales. Antes de analizar las implicancias económicas de esa disposición del Código Andino, en particular, nos referiremos brevemente a las justificaciones del resto de ellas.

Respecto de la selectiviclad en la autorización de IED y su exclusión de ciertos sectores, la Decisión 24 no introduce nada nuevo, ya sea para América Latina como para otros países clesarrollados. Los Estados Unidos excluyen la IED del transporte marítimo costero $y$ algunos Estados no lo permiten en actividades bancarias y financieras. Por otra parte la acumulación de riqueza en manos de los países árabes ha proporcionado buenos ejemplos de lo extendido que puede ser el temor de llegar a ser muy "dependiente" de inversionistas extranjeros, aunque el control que la inversión árabe pudiera llegar a tener sobre las economías de páses tales como Alemania o los Estados Unidos es muchísimo menor que la influencia que cualquie-

cado común con aranceles reclucidos a partir de 1970 (es decir, en el momento en que se inicia la liberalización del comcrcio regional) siempre que expresen formalmente al gobicrno del pais receptor su intención de transformarse en entidades mixtas o nacionales en el futuro, de acuerdo con el calendario especificado en la Decisión 24. 
ra de estos últimos países tiene en muchas naciones en vías de desarrollo. ${ }^{7}$

El requisito de inscripción es esencial como primer paso para lograr que los países obtengan un mejor conocimiento de los efectos de Ia IED en sus economias, de las necesidades futuras de divisas (para repatriar capitales y utilidades) y de Ias condiciones bajo las que se deben negociar futuras inversiones. El intercambio de esta información es también vital para que los países puedan aprovechar las posibilidades de una acción concertada en el mercado común.

Las razones principales que se han tenido para restringir la adquisición de compañias nacionales establecidas por parte de accionistas extranjeros han sido, en primer lugar, impedir que ellos obtengan enormes ventajas de su poder financiero muy grande en comparación con inversionistas locales en las Bolsas de Valores nacionales, normalmente deprimidos y, en segundo lugar, evitar una "descapitalización" nacional como resultado del gasto en consumo del ingreso obtenido por ventas de capital. La limitación impuesta al crédito local tiene una razón de ser similar, especialmente debido a que el crédito interno tiende a ser subvencionado cuando las tasas de inflación son altas.

Con respecto a los pagos por concepto de regalias, patentes y créditos de compañias matrices, existe considerable evidencia empírica en el sentido de que ellos han sido utilizados primordialmente como mecanismos para transferir ganancias hacia el exterior, evitando el pago de impuestos. Además, las patentes y licencias con frecuencia fuentes otorgadas con cláusuias restrictivas $\$$. Por lo tanto, la Decisión 24 ha perseguido limitar esas prácticas.

La limitación de la repatriación de las utilidades en $14 . \%$ del capital comercial se ha prestado para gran confusión. La Decisión 24 no define claramente la base sobre la cual se debe aplicar esta tasa, si se refiere a utilidades netas (libres de impuesto), ni se aplica a cada año por separado, etc. ${ }^{9}$. En general, las interpretaciones van desde considerarla como un limite absoluto sobre las utilidades por parte de los más críticos del Código como conjunto, hasta su interpretación como una simple regulación de los efectos de balanza de pagos de la repatriación de las utilidades. Esta disposición también plantea confusiones respecto de lo que pueden hacer las empresas

7Sobre la intervención del Deutsche Bank, destinada a evitar la participación áratse en el capital de Daimler-Benz, véase The Economist, cnero 18, 1975.

8En Chile, por ejemplo, el $91 \%$ de los contratos de patentes de empresas manufactureras restringian las exportaciones de las mercaderias producidas bajo esas patentes. Véase Moyano (1972).

oDanino (1975). 
que tienen utilidades que sobrepasan el $14 \%$ y que por alguna razón no desean ser reinvertidas.

En la práctica, la norma sobre el $14 \%$ parece reportar más perjuicios que beneficios para los países andinos por razones de "imagen" antes que de carácter propiamente económico. Es una disposición altamente "visible", la cual probablemente tiende a desalentar a algunos inversionistas potencialmente convenientes, sin acarrear beneficios compensatorios para los paises receptores que no se puedan obtener por otros medios alternativos.

La principal preocupación no debería ser la de poner un "techo" cxport a las utilitlades como tales, sino eliminar las condiciones que producen tasas de utiliclades "excesivas" (presumiblemente monopólicas). El uso de derechos arancelarios e impuestos pueden constituir políticas más apropiadas para cambiar dichas condiciones. En todo caso, la disposición del $14 \%$ ha tenido un electo politico positivo en términos del apoyo que la Decisión. 24 y todo el movimiento de integración andino han recibido de varios países y grupos sociales dentro de ellos. Por consiguiente, podria no ser aconsejable quc simplemente se elimine ahora que ya ha sido establecida.

El problema podría ser resuelto mejor mediante una definición y una interpretación adecuada de la disposición en referencia, lo cual pucde hacerse en el reglamento común que debe formularse para implementar la Decisión 24 como un todo.

La fórmula sobre transformación de empresas extranjeras en nácionales contenida en la Decisión 24 también ha sido objeto cle interpretaciones erradas, especialmente por parte de los grupos más críticos del Estatuto Andino de capitales en general. Aquí se intentará aclarar sólo algunos puntos fundamentales:

Primero, esa norma no rige para todas las compañias extranjeras instaladas o que deseen hacerlo on la región. La Decisión 24 es muy explicita en afirmar que ella es válida para aquellas que deseen gozar de las ventajas del mercado comín.

Segundo, la transformación no es una obligación forzosa, sino una condición para las empresas; más aún, son los propietarios de cllas quienes tienen la iniciativa para decidir transformarlas o no, si es que estiman que las ventajas del mercado ampliado les compensa los eventuales costos envueltos en la conversión a empresas mixta o nacional.

Tercero, la norma bajo estudio no es equivalente a una mera forma encubierta de expropiación gradual ${ }^{10}$. Es muy probabie que

xopor olla parte, las acciones que el inversionista decida ceder son vendidas y no regaladas a los accionistas nacionales, asi es que el extranjero recibe una compensación: por su capital. 
no sea necesario para muchos inversionistas extmanjeros vender parte del capical que efectivamente han invertido en el Area Andina. Sólo tienen que ir cediendo un control mayoritario a las empresas que poseen, para lo cual puede captar el capital adicional que necesiten de inversionistas locales, hasta que cslos últimos comprendan el $51 \%$ del capital total. ${ }^{11}$.

Debiclo a que en la práctica el inversionista extranjero decidirá transformar sus empresits en nacionales cuando desee hacer exportaciones libres de aranceles a otros paises asociados, esto significa que el capital para la expansión de la producción se obtendrá con todá probabilidad de los inversionistas nacionales, pero a través de ese método -comparado con el otorgamiento de créclitos, por ejemploestos últimos participarán en las utilidacies y la gestión cle las cmpresas.

En cuarto lugar, la norma sobre transformación constituye sólo un método distinto para efectuar Ia repatriación de los capitales cxtranjeros invertidos. En este caso, ella se realizará implicitamente en relación directa con el precio que obtenga el inversionista extranjero por las acciones que venda.

Es dificil realizar una evaluación cle los efectos que pudiera tener la fórmula sobre transformación de empresas para los paiscs receptores de inversiones. Comprende muchos aspectos del fenómeno simultáneamente, aunque esencialmente se puede interpretar como uma forma en la cual Ios países receptores participan en las utilidades de las firmas extranjeras, y en ese sentido deberia ser evaluado en comparación con otras alternativas cquivalentes, principalmente los impuestos. La fórmula per se también afecta a) el volumen y tipo de capital extranjero translerido a los paises, b) el valor y secuencia de la repatriación de capital, c) las utilidades netas remesadas por los inversionistas, $y d$ d) cuestiones que atañen a la gestion $y$ control de las empresas. Estos factores están íntimamente relacionados y todos ellos, en conjunto, determinan los bencficios que percibirá el país receptor de IED.

En la próxima sección, nos concentraremos sólo en el primero de los efectos mencionados, porque es aquél en el cual se han concentrado más los debates. listo no quiere decir, sin embargo, que sca necesariamente cl efecto más importante de la Decisión 24 debido a que los beneficios de la IED para los paises receptores dependen no

IIObsérrese además que el inversionista cxtraijero puede retener control solure su empresa con el $40 \%$ del stock de capilal o menos, si es que el resto se divide entre dos o mis inversionistas nacionales que posean porciones similares de las acciones. 
sólo de la cantidad de capital y otros 1ecursos externos que obtiene, sino también de las condiciones o los términos en que los hace.

\section{ALGUNOS ANTECEDENTES SOBRE LOS EFECTOS DE LA DECISYÓN 24 SOBRE EL FLUJO DE INVERSIONES}

La reacción inmediata de la mayoría de los inversionistas extranjeros fue considerar la Decisión 24 "muy restrictiva". Sin embargo, las actitudes variaron, particularmente cle acuerdo a la nacionalidad de los inversionistas. Los norteamericanos eran los que se oponían más, en tanto que los accionistas europeos y japoneses estaban más llanos a aceptarla. La critica más fuerte y abierta provino del Consejo de las Américas ("Council of the Americas"), organización que representa a los inversionistas norteamericanos en América Latina.

En febrero de 1971, dicha institución envió un extenso documento a los gobiernos andinos, a las organizaciones empresariales, a los legisladores norteamericanos, a los jefes de organizaciones internacionales y a la prensa, criticando el Código Andino de Inversiones ${ }^{12}$. Esencialmente, el Consejo sostenía que, por un lado, la Decisión 24 desalentaría seriamente, y en muchos casos, eliminaría por completo toda nueva inversión directa en los países andinos, mientras, por otro lado, serviría para descartar cualquier papel que pudiera jugar la inversión extranjera en el Mercado Común Andino. Por consiguiente, el Consejo de las Américas concluyó que la Decisión 24 haria más lento el proceso de desarrollo económico general, debilitando además los sectores privados nacionales. ${ }^{13}$

La reacción del Consejo de las Américas fue no sólo desproporcionada, sino además basada en estudios poco rigurosos, como lo señalaron incluso algunos inversionistas norteamericanos ${ }^{14}$. Es difícil y

I2Véase Council of the Americas (1971).

13Resulta fascinante observar la redacción de las declaraciones del Consejo de las Américas, especialmente la forma en que tratan de encontrar aliados en las comunidades empresariales nacionales y en los politicos norteamericanos. Cuando fracasaron esas tácticas, despućs de 1973, el Consejo comenzó a destacar las divergencias de intereses individuales de los paises andinos con respecto a la IED. Esa es la tendencia reciente, especialmente explotando las diferencias de Chile con sus otros asociados, que terminó por tener éxito como lo atestigua el retiro de ese pais del Pacto. Aún queda por hacer una investigación acuciosa del papel y comportamiento de ése $y$ de otros organismos de inversionistas. El trabajo dc Wionzcek (197I) es un estudio pionero extremadamente intercsante acerca de las presiones de los intereses foráneos sobre los gobiernos durante la formulación e implementación de la Decisión 24.

14Véase Business Latin America (1971), pp. 121-123 y Diaz Alcjandro (1971). 
demasiado temprano para realizar una evaluación integral del impacto de la Decisión 24, aun considerando solamente cl aspecto restringido de los cambios experimentados en los flujos de inversión extranjera. Además, algunos importantes países andinos, como Chile y Perú, han sido objeto de desarrollos políticos y económicos completamente independientes de la Decisión 24, que han afectado considerablemente la afluencia de inversión extranjera. Por otra parte, Venezuela adoptó la Decisión 24 sólo en 1973.

No obstante, lo menos que se puede afirmar con certeza sobre la base de las cifras disponibles es que la inversión extranjera no ha disminuido, ni ha crecido más Ientamente debido a la Decisión 24. En Colombia -el país que posee estadisticas más recientes y completas- el total de inversión extranjera ha aumentado sustancialmente, aunque los inversionistas debieron enfrentar un período de gran incertidumbre debido a que el gobierno estaba, en la práctica, aplicando las disposiciones de Ia Decisión 24 aún cuando se estaban planteando dudas sobre su legalidad. A pesar de ello el flujo anual cle inversión extranjera aumentó desde un promedio de 13,1 millones de dólares en el período comprendido entre 1968 y 1970, a 34,5 entre 1971 y 1973; sólo en manufacturas, se elevó desde 12,7 a 22,0 millones de dólares entre ambos períodos (casi un $75 \%$ de aumento) ${ }^{15}$. Algunos datos preliminares para 19744 y 1975 indican que la afluencia de IED a todos los sectores ha crecido hasta unos 60 millones de dólares por año ${ }^{16}$.

Aun en Chile la inversión extranjera ha aumentado recientemente a pesar de la imagen del país en el exterior, de la incertidumbre acerca de su futuro y de las expectativas de que el país lograra evitar la aplicación de algunas normas de la Decisión 24, lo cual tiende a provocar demoras en la materialización de los proyectos de inversión extranjera. No obstante, se han autorizado proyectos por valor de 285 millones de dólares entre fines de 1973 y fines de 1975. De éstos aproximadamente 70 millones correspondieron a inversiones en el sector manufacturero, aunque la mayoría fue en empresas antiguas que estaban "poniéndose al día" por la falta de inversiones en el período $1971-73^{17}$. Resulta interesante hacer notar, sin embargo, que cerca de 40 de esos 70 millones fueron autorizados en los últimos

16Datos del Banco de la República, Colombia, citados por Caballero (1975), Cuadro 9 .

1oVéase las declaraciones del Presidente de la República de Colombia en Grupo Andino, No 52, p. 12.

17Comitć de Inversiones Extranjeras. CORFO, comunicado de prensa, setiembre, 1975 . 
tres meses de 1975, después de que el gobierno habia accediclo a acatar las principales disposiciones de la Decisión 24.

Perú ha continuado recibiendo inversión extranjera a pesar de las disposiciones legales que exigian tanto a las empresas nacionales como extranjeras vender acciones a sus trabajadores $y / 0$ formar empresas mixtas con el Estado. Los proyectos que están más intimamente relacionados con el proceso de integración incluyen una inversión de 16 millones en productos químicos, realizacla por la Bayer y un proyecto de por 8 millones de dólares de la Massey-Ferguson y Perkins-Volvo para tractores y otros equipos de transporte. Las inversiones en minería -realizadla principalmente por empresas japonesas - tambièn se han manteniclo altas. 18

Para Ecuador y Bolivia, que son los países andinos más pequeños, Ia situación es más desconocida, debido a que están recién comenzanclo a recoger estadísticas acerca de la inversión extranjera. Existe acuerclo general en el sentido de que Ecuador ha tenido un "boom" clo inversiones en casi todos los sectores, motivado por el reciente descubrimiento de petróleo. Existen indicios de una considerable participación de empresas extranjeras en la significativa expansión de las exportaciones de manufacturas ecuatorianas hacia el Grupo anclino ${ }^{10}$

Sobre Bolivia no existen datos completos acerca de stocks o flujos antes de 1970. El Censo de 1967 realizaldo por el Departamento de Comercio de los Estados Unidos da un stock total de 60 millones de dólares de inversión norteamericana directa; de éstos, sólo $3 \mathrm{mi}-$ llones se invirtieron en manufacturas. Durante el solo periodo comprendicto entre 1972 y 1974 , sin embargo, la inversión adicional en manufacturas fue de 4,4 millones de dólares, de los cuales 1,2 millones corresponderían a inversión norteamericana directa ${ }^{20}$. Tinalmente, vale la pena destacar que sólo un proyecto establecido especificamente para Bolivia en el Programa Sectorial Metal Mecánico - una empresa mixta de la Atlas-Copco, que comenzó su producción hacia fines de 1975 - ya ha comenzado una inversión de más de 9 millones de dólares.

La única serie de datos homogéneos sobre IED que puede utilizarse para establecer comparaciones entre el periodo inmediatamente antes y después de la implementación de lá Decisión 24 (en 1971) es la de la inversión directa de los Estados Unidos. Esta información, sin embargo, subestima el incremento de toda Ia IED en los países andinos después de la Decisión 24, porque se ha observaclo que los

I8Pate (1975), pp. 8.20 .

29Véase Moncada (1975) y Crupo Andino, varios números.

20Grupo Andino, № 52, dicicmbre 1975, pp. 11-12. 
inversionistas nortcamericanos han reaccionado ante esa decisión invirtiendo menos que los europeos o que los japoneses 21 . El cuadro I presenta los clatos sobre el valor de libros del stock de las inversiones clirectas cle los Estacios Uniclos en el Grupo Anclino.

CUADHO NO 1

VALOR DE LIBROS DE LA JNVERSION EXTRANJERA DIRECTA NORTEAMERICANA EN EL SECTOR MANUFACTURERO DEL GIIUPO ANDINO

(millones de dólares do cada año)

Stocks at final de cala año

\begin{tabular}{|c|c|c|c|c|c|c|c|c|}
\hline & Colombic: & Chile & Perit & Vonezucla & $\begin{array}{c}\text { rumo Asuli } \\
\text { crecploto } \\
\text { Venczuclat }\end{array}$ & $\begin{array}{c}\text { Grupo } \\
\text { Andluno } \\
\text { Toial }\end{array}$ & $\begin{array}{l}\text { nupo Antion } \\
\text { recepto } \\
\text { Venezucta }\end{array}$ & $\begin{array}{l}\text { Grupo } \\
\text { Amtlino } \\
\text { Total }\end{array}$ \\
\hline 1967 & 199 & 61 & 98 & 310 & 351 & 661 & 18 & 30 \\
\hline 1968 & 195 & 68 & 96 & 376 & 357 & 733 & 6 & 72 \\
\hline 1069 & 220 & 65 & 97 & 413 & 382 & 795 & 25 & 69 \\
\hline 1970 & 235 & 66 & 92 & 462 & 393 & 855 & 11 & 60 \\
\hline 1971 & $250 \mathrm{f}$ & 50 & 92 & 510 & 398 & 905 & 5 & 53 \\
\hline 1972 & 264 & 40 & 89 & 552 & 399 & 951 & 1 & 98 \\
\hline 1973 & 325 & 50 & 164 & 523 & 539 & 1.062 & 140 & $1 ! i$ \\
\hline 1974 & 375 & 43 & $1: 59$ & 609 & 577 & 1.186 & 38 & 194 \\
\hline
\end{tabular}

FUENTE: U. S. Departmenl of Commerce, Surcey of Current Business, varins numeros.

El Cuadro 1 muestra que, en general, el capital norteamericano en el sector industrial del Grupo Andino, ha seguido aumentandio después de la implementación de la Decisión 24 realizada por la mayoría de los paises en 1971 y por Venezuela en 1973. Fa habido suspensiones temporales de nuevas inversiones durante los periodos de incertidumbre sobre la aplicación cle la Decisión 24 entre 1971 y' 1972 en Colombia y entre 1972 y 1973 en Venezuela. Pero clespués de esos años, las inversiones de Ios Estados Uniclos han aumentado lo suficiente como para incluso compensar las bajas inversiones realizatdas durance los periodos de incertidumbre ${ }^{22}$.

La inversión neta anual -el aumento del stock de capital norte-

21Véase Council of the Amcricas, Inc. (1973) y especialmente, el articulo de Pate $(1973)$ en ese voltumen.

22obsérvense también las redacciones en la inversión directa de los Estadlos Unidos en Chile duranie el Gobierno de Allende, que probablemente serin revertidas significativamente a partir de 1975 . 
americano en el Grupo Andino cada año- excluyendo a Venezuela, subió desde aproximadamente 14 millones como promedio durante los cuatro años que precedieron la implementación de la Decisión 24 (1967-70) hasta 46 millones en los cuatro años inmediatamente siguientes"3. Por lo tanto, aun si se considera la rápida depreciación del dólar producida en este último periodo, de todas maneras la inversión de los Estados Unidos ha continuado en aumento después de la implementación de la Decisión 24.

Finalmente, vale la pena hacer notar que los gastos de capital (en plantas, propiedad y equipos) realizados en el Grupo Andino por inversionistas directos de los Estados Unidos, también han continuado aumentando luego de la implantación de la Decisión 24. Los gastos de capital foráneo subieron desde un promedio de 114 millones de dólares en el período comprendido entre 1967 y 1970 hasta 127 millones de dólares entre 1971 y 1974. Pero, lo que es más importante, los gastos de capital esperados para 1975 y 1976 -basados en encuestas bi-anuales realizadas por el Departamento de Comercio de los Estados Unidos- indican que los inversionistas habían gastado 168 millones de dólares en el Grupo Andino durante 1975 (según encuesta de junio de 1975 y gastarían 170 millones en 1976 (encuesta de diciembre de 1975). ${ }^{24}$

\section{CONCLUSIONES}

El establecimiento de una política especifica que permita regular la operación de las empresas extranjeras en el mercado común constituye una necesidad que surge de los diferentes efectos que tiene la liberación del comercio regional sobre las firmas nacionales y extranjeras. Los cambios en los aranceles también tienen efectos sobre los ingresos o utilidades de ellas: implican una redistribución interna del ingreso en el caso de las empresas nacionales, pero implican una redistribución del ingreso internacional entre los países receptores $y$ las compañías extranjeras cuando estas últimas participan en el mercado común.

La Decisión 24 ha sido concebida básicamente para compensar lor efectos redistributivos negativos $y$, por lo tanto, tiene una importante

23Incluycndo a Venezuela, la invers:ón neta norteamericana durante esos dos periodos subió de un promedio anual de 56 millones a 82 millones.

24 Survey of Current Business, marzo 1976, pp. 20-28. 
justificación económica. En consecuencia, debería ser mantenida, pero complementada con el diseño e ìmplementación del sistema de aranceles externos comunes y de progxamas sectoriales de desarrollo industrial como parte de una política integral hacia el capital extranjero. Ese enfoque ha estado muy en el espíritu de quienes formularon el Acuerdo de Cartagena, pero los gobiernos andinos, al tomar decisiones concretas, han tendido a dejarlo de lado.

Queda aún por verse los efectos. globales que en definitiva tendrá la Decisión 24 sobre los beneficios captados por los países de la inversión extranjera. Es difícil predecir los resultados más probables, porque dependen de muchas condiciones diferentes. Sin embargo, se sabe que aquellos que pronosticaron un claro perjuicio para los paises debido al cese total de nuevas inversiones extranjeras en el Area Andina luego de haberse aprobado el Régimen de Tratamiento Común en 1971, estaban completamente equivocados. En general, ese régimen no parece plantear condiciones inadmisibles para inversionistas inteligentes, sensatos y experimentados, mientras que es probable que las inversiones hechas bajo las condiciones estipuladas sean más beneficiosas para los países andinos.

Una de las principales ventajas de la Decisión 24 es que -siendo un tratado internacional- probablemente seguirá teniendo mayor estabilidad que la que normalmente han tenido las políticas nacionales de inversión extranjera. En efecto, este ha sido el caso durante sus cinco años de aplicación. En el transcurso de ese período ha sobrevivido al cambio de muchos gobiernos en los países andinos, algunos de ellos con orientaciones diametralmente opuestas. La restricción más importante para las inversiones de largo plazo-que podrían haber tenido un impacto más positivo sobre el desarrollo de los paises receptores que aquellos de corto plazo - ha sido la inseguridad acerca de la permanencia de políticas respecto a la IED. La experiencia les ha demostrado a los inversionistas que uno de los peligros que corren cuando intentan condiciones demasiado favorables para sus inversiones es que ellas pueden ser modificadas muy drásticamente después de un corto periodo. Por consiguiente, prefieren no invertir tanto en proyectos de largo plazo como lo harían bajo condiciones, o dentro de políticas, más estrictas pero más estables. En casos de incertidumbre prefieren invertir en proyectos en los que puedan recuperar el capital en el más corto tiempo posible. La inseguridad con respecto a las politicas de inversión extranjera es un factor que afecta negativamente a ambas partes $\rightarrow$ al pais receptor y al inversionista- y no reporta beneficios para ninguno de los dos. 
En síntesis, el Régimen Común para el Tratamiento de capitales extranjeros on el Grupo Andino, no sólo constituye un conjunto de normas eficientes, realistas y equitativas para asegurarse mayores benelicios de participar en un proceso de integración, sino que es también conveniente de aplicar por parte de cualquier pais como lo demuestih el hecho de que se ha usado como modelo en diversas regiones del munclo. 